\title{
A Phase I study of cyclin-dependent kinase inhibitor, AT7519, in patients with advanced cancer: NCIC Clinical Trials Group IND 177
}

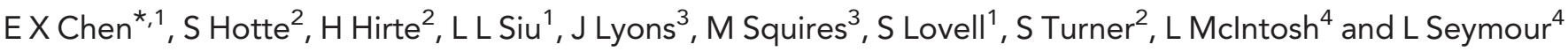 \\ ${ }^{1}$ Princess Margaret Cancer Centre, University Health Network, Room 5-719, 610 University Avenue, Toronto, Ontario, Canada; \\ ${ }^{2}$ Juravinski Cancer Centre, Hamilton Health Sciences, Hamilton, Ontario, Canada; ${ }^{3}$ Astex Pharmaceutics, Cambridge, UK and \\ ${ }^{4}$ NCIC Clinical Trials Group, Kingston, Ontario, Canada
}

Background: AT7519 is a small-molecular inhibitor of multiple cyclin-dependent kinases (CDKs). It shows encouraging anti-cancer activity against multiple cell lines and in tumour xenografts. This phase I study was conducted to evaluate the safety and tolerability of AT7519 given as 1-h intravenous infusion on days 1, 4, 8 and 11 every 3 weeks.

Methods: Patients with advanced refractory solid tumours or non-Hodgkin's lymphoma were enroled. Dose escalation occurred in a 3+3 manner based on toxicity assessment. Pharmacokinetic samples were collected after first AT7519 infusion, whereas pharmacodynamics (PD) samples were obtained in selected patients.

Results: Thirty-four patients were enroled, and 32 received study treatments over 4 dose levels. Dose-limiting toxicities included mucositis, febrile neutropenia, rash, fatigue and hypokalemia. The recommended phase II dose (RP2D) was $27.0 \mathrm{mg} \mathrm{m}^{-2}$. Ten of 19 patients evaluable for efficacy had stable disease as the best response (median duration: 3.3 months; range: 2.5 to 11.1 months). There was no clinically significant QTc prolongation. There was an apparent dose proportional increase in AT7519 exposure. The PD studies showed reduction in markers of CDK activity in selected patients' skin biopsies post treatment.

Conclusions: AT7519, when administered as an intravenous infusion on days 1, 4, 8 and 11, was well tolerated. The RP2D is $27.0 \mathrm{mg} \mathrm{m}^{-2}$. At this dose level, plasma AT7519 concentrations were above the biologically active concentrations, and preliminary anti-cancer activity was observed in patients. This dosing schedule is being further evaluated in multiple phase II studies.

Cyclin-dependent kinases (CDKs) are protein kinases involved in cell cycle regulation and mRNA synthesis and processing (Johnson and Shapiro, 2010; Cicenas and Valius, 2011). Aberrant expression or dysregulation of CDKs has been implicated in the pathogenesis and progression of multiple human cancers (Kusume et al, 1999; Kouroukis et al, 2003; Kim et al, 2008; Poomsawat et al, 2010); hence, the inhibition of CDKs is being extensively investigated as anti-cancer therapy. There are multiple CDK inhibitors in clinical development at the present time (Cicenas and Valius, 2011; Canavese et al, 2012).

AT7519, a small-molecule multi-CDKs inhibitor, was synthesised using fragment-based medicinal chemistry approaches, linked to high-throughput X-ray crystallography (Wyatt et al, 2008).
It potently inhibits CDK1, CDK2, CDK4-6 and CDK9 and shows strong anti-proliferative activity against a wide range of human cancer cell lines, including both solid tumours and haematological malignancies (Squires et al, 2009). Furthermore, AT7519 induces apoptosis in both multiple myeloma cells and other B-cell malignancies by inhibiting RNA polymerase II phosphorylation (Santo et al, 2010; Squires et al, 2010). Based on these encouraging pre-clinical activities, AT7519 is currently in clinical development. In pre-clinical studies, intermittent cyclic dosing schedules were found to provide the best efficacy and tolerability, thus, two phase I studies were initiated simultaneously to evaluate two intermittent dosing schedules (Squires et al, 2009). A phase I study of AT7519 has been reported in which it was administered as intravenous

*Correspondence: Dr EX Chen; E-mail: eric.chen@uhn.ca

Received 8 August 2014; revised 23 September 2014; accepted 9 October 2014; published online 13 November 2014

(c) 2014 Cancer Research UK. All rights reserved 0007-0920/14 
infusion over $1 \mathrm{~h}$ on five consecutive days every 3 weeks (Mahadevan et al, 2011). Unfortunately the study was discontinued without establishing the maximal tolerated dose due to dosedependent increases in QTc. In the current study, a second intermittent dosing schedule was evaluated, where AT7519 was administered on days $1,4,8$, and 11 every 3 weeks. The primary objectives of the study were to evaluate the safety and tolerability of AT7519 administered in this schedule and to determine the recommended phase II dose (RP2D). Secondary objectives included determining pharmacokinetics and pharmacodynamics of AT7519 and collecting preliminary evidences of anti-tumour activities.

\section{PATIENTS AND METHODS}

Eligibility. Patients were eligible if they had histologically proven advanced solid malignancies or non-Hodgkin's lymphoma, refractory to standard therapies. For patients with solid malignancies, up to three prior chemotherapeutic regimens for metastatic disease were permitted, whereas the number of chemotherapeutic regiments including autologous stem cell transplant was not limited for patients with non-Hodgkin's lymphoma. Other key eligibility criteria included age $\geqslant 18$ years, performance status (ECOG) $0-2$, adequate haematological, renal and hepatic functions (absolute neutrophil count $\geqslant 1.5 \times 10^{9} 1^{-1}$, platelets $\geqslant 100 \times 10^{9} 1^{-1}$, bilirubin $\leqslant$ upper limit of normal, aspartate transaminase /alanine transaminase $\leqslant 2 \times$ upper limit of normal or $5 \times$ upper limit of normal in patients with documented liver metastases, creatinine $\leqslant 1.25 \times$ upper limit of normal or calculated creatinine clearance $\geqslant 50 \mathrm{ml} \mathrm{min}^{-1}$ ). Prior chemotherapy or radiotherapy must have been completed at least 21 days prior to study registration and patients must have recovered from side effects of previous therapies.

Patients were excluded if they had untreated brain or meningeal metastasis, or any other significant medical condition that could potentially affect safety. Patients with child-bearing potential had to use two forms of effective contraceptives. The study was approved by institutional review boards at both participating institutions and conducted in accordance with applicable federal and institutional guidelines. All patients gave written, informed consent prior to study initiation.

Study design and treatment. AT7519 was administered as an intravenous infusion over $1 \mathrm{~h}$ on days $1,4,8$ and 11 every 3 weeks starting at a dose of $14.4 \mathrm{mg} \mathrm{m}^{-2}$. The starting dose was based on observations from the previous phase I study of AT7519 in which dose-limiting toxicity (DLT) was initially seen at $14.4 \mathrm{mg} \mathrm{m}^{-2}$ per day $\times 5$ days (Mahadevan et al, 2011). Doses were increased at $20-50 \%$ increments (Table 2). The study treatment was continued until there was evidence of disease progression, unacceptable toxicity or withdrawal of consent. At least three patients were enroled initially at each dose level. If one out of three patients experienced DLT, at least three additional patients were enroled at the same dose level. For dose escalation to occur, no more than two out of six patients must have experienced DLT at that dose level. If $\geqslant$ two out of three or two out of six patients experienced DLT at a given dose level, that dose level was considered to be the maximally tolerated dose level and the next lower dose level was considered to be RP2D.

The DLT was defined as grade 3 or higher non-haematological toxicity (excluding alopecia or inadequately treated nausea and vomiting) related to AT7519, grade 4 neutropenia lasting $\geqslant 5$ days, grade 4 thrombocytopenia, febrile neutropenia or thrombocytopenic bleeding requiring blood transfusion, persistent grade 2 or grade 3 or 4 neurotoxicity, any other toxicity of concern to investigators and delay of planned cycle 2 treatment for $>14$ days in cycle 1 .

Assessment. Baseline assessments included a medical history, physical examination and laboratory investigations including complete blood counts with differentials, renal, hepatic and metabolic functions. Toxicity assessment was based on Common Terminology Criteria for Adverse Events, version 3.0, in each cycle. Radiological assessment was performed after every two cycles of treatment and response was determined according to Response Criteria for Solid Tumors version 1.1 (Therasse et al, 2006).

Pharmacokinetic analysis. Blood samples were collected from a peripheral vein prior to AT7519 infusion, 30 and $60 \mathrm{~min}$ into the infusion, and at 5, 10, 15 and $30 \mathrm{~min}$, then $1,2,4,6,8,24$ and $72 \mathrm{~h}$ after completion of infusion on day 1, cycle 1. Plasma AT7519 concentrations were determined using a HPLC-tandem mass spectrometry method similar to that reported previously (Mahadevan et al, 2011). Pharmacokinetic parameters were calculated using non-parametric methods (WinNonlin Version 5.3, Pharsight Corp., Mountain View, CA, USA).

Pharmacodynamic analysis. At the RP2D level, skin punch biopsies and tumour biopsies were obtained from consenting patients pre- and $24 \mathrm{~h}$ after the completion of AT7519 infusion. These samples were analysed for proliferating cell nuclear antigen (a cell proliferation marker), nucleophosmin (NPM, a direct CDK2 substrate) and Ki67 as described previously (Mahadevan et al, 2011).

ECG analysis. After the completion of dose level 1, the study protocol was amended to exclude patients with congenital long QT syndrome, QTc $\geqslant 460 \mathrm{~ms}$ on baseline ECG, history of QT prolongation with other medications or on medications that potentially affect QTc intervals after one death was reported in a patient with progressive QTc prolongation from another phase I study (Mahadevan et al, 2011). Furthermore, 12-lead ECGs were obtained immediately prior to, and immediately following, each AT7519 infusion on days 1, 4, 8 and 11 of cycle 1 . A confirmatory ECG was obtained within $48 \mathrm{~h}$ if any QTc abnormality was detected. Machine recorded QT intervals with Bazett correction (Bazett, 1920) were collected. Finally, five patients at the RP2D level underwent $24 \mathrm{~h}$ ambulatory ECGs recording immediately after completion of AT7519 infusion on cycle 1. All ECGs recordings were reviewed by an expert cardiologist independent of the study.

\section{RESULTS}

A total of 34 patients were enroled, one patient withdrew consent and one patient was hospitalised prior to study therapy. Thus, 32 patients received study treatments (Table 1 ). Thirty (94\%) patients had advanced solid tumours and two patients (6\%) had nonHodgkin's lymphoma. Patients received a median of 2 prior chemotherapy regimens and one patient with non-Hodgkin's lymphoma had prior autologous stem cell transplant.

Patients received a total of 88 cycles of AT7519 (median: 2 cycles; range: 1-10) (Table 2). No DLTs were encountered at the $14.4 \mathrm{mg} \mathrm{m}^{-2}$ dose level. Among the first four patients enroled at the $21.6 \mathrm{mg} \mathrm{m}^{-2}$ dose level, one patient developed DLT (grade 3 rash, mucositis and infection without neutropenia). Three additional patients were enroled and none experienced DLT. One of the first three patients enroled at the $27.0 \mathrm{mg} \mathrm{m}^{-2}$ dose level developed DLT (grade 3 mucositis and fatigue). Three additional patients were enroled, one of whom developed grade 3 aspartate transaminase elevation. However, the relationship of this event to AT7519 was not clear as the patient had coincidental viral infection at the same time. Another four patients were enroled at this dose 
level, and no patients experienced DLT. Therefore, AT7519M dose was escalated to $32.4 \mathrm{mg} \mathrm{m}^{-2}$. Among the initial three patients enroled, one patient experienced DLT (grade 3 fatigue). Two additional patients were enroled at this dose level, both of whom experienced DLTs (febrile neutropenia and grade 3 hypokalemia and mucositis). Therefore, the $32.4 \mathrm{mg} \mathrm{m}^{-2}$ dose was declared the maximum tolerated dose and the $27.0 \mathrm{mg} \mathrm{m}^{-2}$ dose the recommended dose for future phase 2 studies (RP2D). Five additional patients were enroled at the RP2D dose level and none of them experienced any DLT.

The most common adverse events are summarised in Table 3. They included fatigue (53.1\%), mucositis (53.1\%), vomiting (34.4\%) and nausea (31.7\%). However, most of these events were grade 1 and 2 in severity, with $<10 \%$ patients experienced grade 3 fatigue and mucositis. Anaemia (87.5\%) and lymphopenia (84.4\%) were the two most common haematological toxicities seen, with

\section{Table 1. Baseline demographics $(N=32)$}

\begin{tabular}{|c|c|}
\hline \multicolumn{2}{|l|}{ Age (years) } \\
\hline $\begin{array}{l}\text { Median } \\
\text { Range (years) }\end{array}$ & $\begin{array}{c}61 \\
40-77\end{array}$ \\
\hline Gender & $N(\%)$ \\
\hline $\begin{array}{l}\text { Male } \\
\text { Female }\end{array}$ & $\begin{array}{l}13(40.6) \\
19(59.4)\end{array}$ \\
\hline Performance status (ECOG) & $N(\%)$ \\
\hline $\begin{array}{l}0 \\
1 \\
2\end{array}$ & $\begin{array}{r}9(28.1) \\
19(59.4) \\
4(12.5)\end{array}$ \\
\hline Tumor types & $N(\%)$ \\
\hline $\begin{array}{l}\text { Colorectal cancer } \\
\text { Head and neck cancer } \\
\text { Non-small-cell lung cancer } \\
\text { Pancreatic cancer } \\
\text { Oesophageal cancer } \\
\text { Gastric cancer } \\
\text { Breast cancer } \\
\text { Non-Hodgkin's lymphoma } \\
\text { Melanoma } \\
\text { Thyroid cancer } \\
\text { Other }\end{array}$ & $\begin{array}{l}4(12.5) \\
3(9.4) \\
3(9.4) \\
3(9.4) \\
2(6.3) \\
2(6.3) \\
2(6.3) \\
2(6.3) \\
2(6.3) \\
2(6.3) \\
7(21.9)\end{array}$ \\
\hline Number of sites of disease & $N(\%)$ \\
\hline 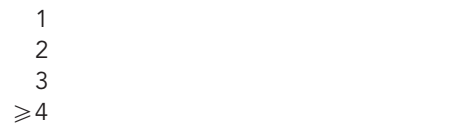 & $\begin{aligned} 2 & (6.3) \\
9 & (28.1) \\
7 & (21.9) \\
14 & (43.8)\end{aligned}$ \\
\hline Prior therapy & $N(\%)$ \\
\hline $\begin{array}{l}\text { Chemotherapy } \\
\text { Radiotherapy } \\
\text { Hormone/immune therapy }\end{array}$ & $\begin{array}{l}29(90.6) \\
21(65.6) \\
3(9.4)\end{array}$ \\
\hline Number of prior chemotherapy regimens & $N(\%)$ \\
\hline $\begin{array}{l}0 \\
1 \\
2 \\
3\end{array}$ & $\begin{aligned} & 3(9.4) \\
9 & (28.1) \\
15 & (46.9) \\
5 & (15.6)\end{aligned}$ \\
\hline
\end{tabular}

$37.5 \%$ of patients developing grade 3 or 4 lymphopenia. Common biochemical adverse events included elevations of aspartate transaminase and alkaline phosphatase, with grade 3 or 4 events observed in $9.4 \%$ and $15.6 \%$ respectively.

Serial on-treatment ECGs were available from 27 patients. All patients had baseline QTc $\leqslant 460 \mathrm{~ms}$, and there were no QTc beyond $480 \mathrm{~ms}$ observed during the study. Among the 24 patients with baseline QTc $\leqslant 450 \mathrm{~ms}, 10$ had transient QTc increases of less than $30 \mathrm{~ms}$ during the study. These changes were not associated with any clinically evident cardiac events. In addition, five patients at the RP2D level underwent 24-h ambulatory ECG monitoring after first AT7519 administration. There were no clinically significant QTc prolongations observed from these recordings.

Anti-tumour activity. Nineteen patients were evaluable for efficacy. There was no complete or partial response seen. Ten patients had stable disease as the best response (median duration: 3.3 months; range: 2.5 to 11.1 months). A 73 -year-old patient with metastatic rectal cancer received 10 cycles of study treatment, with a best response of stable disease. This patient received radiation and three chemotherapy regimens prior to participating in this study. The best response was progressive disease in another nine patients.

Pharmacokinetics. Complete pharmacokinetic profiles were available for 29 patients. Following 1-h intravenous infusion, AT7519 rapidly distributes and its elimination follows first-order kinetics with a mean $\mathrm{t} 1 / 2$ of $13.1 \pm 4.0 \mathrm{~h}$ (Figure 1 ). The plasma clearance was $0.28 \pm 0.261 \mathrm{~min}^{-1} \mathrm{~m}^{-2}$, and the volume of distribution was $289 \pm 2181 \mathrm{~m}^{-2}$. The mean maximal concentration $\left(C_{\max }\right)$ at the $\mathrm{RP} 2 \mathrm{D}$ level was $591 \pm 358 \mathrm{ng} \mathrm{ml}^{-1}$. There was an apparent dose proportional increase in AT7519 $C_{\max }$ and plasma exposures (Figure 2).

Pharmacodynamics. At the RP2D level, skin and tumour biopsies were obtained in four and three patients, respectively, pre-dose and $24 \mathrm{~h}$ after the end of AT7519 infusion. For skin punch biopsies, positively stained cells in a defined area of the epidermis were counted. There was no change in Ki67 in any patient. In contrast, proliferating cell nuclear antigen, another cell proliferation marker, was reduced in two patients; whereas PNPM, a direct CDK2 substrate, was reduced in three of four patients, and there was no change seen in the remaining patient (Figure 3). For tumour specimens, only a percentage of positively stained cells can be estimated. There were no consistent changes observed for proliferating cell nuclear antigen, pNPM and Ki67 in any patient.

\section{DISCUSSION}

AT7519 is a potent inhibitor of multiple CDKs and is currently undergoing clinical development as an anti-cancer agent. A second dosing schedule was evaluated in this study. AT7519 was administered as intravenous infusion over $1 \mathrm{~h}$ on days $1,4,8$, and 11 every 3 weeks. DLTs were mucositis, febrile neutropenia, rash and hypokalemia. These DLTs were similar to those observed

Table 2. The dose escalation scheme and DLTs

\begin{tabular}{|c|c|c|c|}
\hline $\begin{array}{l}\text { Dose level } \\
\left(\mathrm{mg} \mathrm{m}^{-2}\right)\end{array}$ & $\begin{array}{l}\text { No. of patients } \\
\text { treated }\end{array}$ & $\begin{array}{l}\text { No. of cycles } \\
\text { received median (range) }\end{array}$ & No. of patients with DLT \\
\hline 14.4 & 5 & $2(1-4)$ & none \\
\hline 21.6 & 7 & $2(1-10)$ & 1 (grade 3 rash, mucositis, infection) \\
\hline 27.0 & 15 & $2(1-5)$ & 1 (grade 3 mucositis) \\
\hline 32.4 & 5 & $1(1-5)$ & 3 (grade 3 fatigue, febrile neutropenia, grade 3 hypokalemia and mucositis) \\
\hline
\end{tabular}


Table 3. Summary of treatment-related AE by dose level

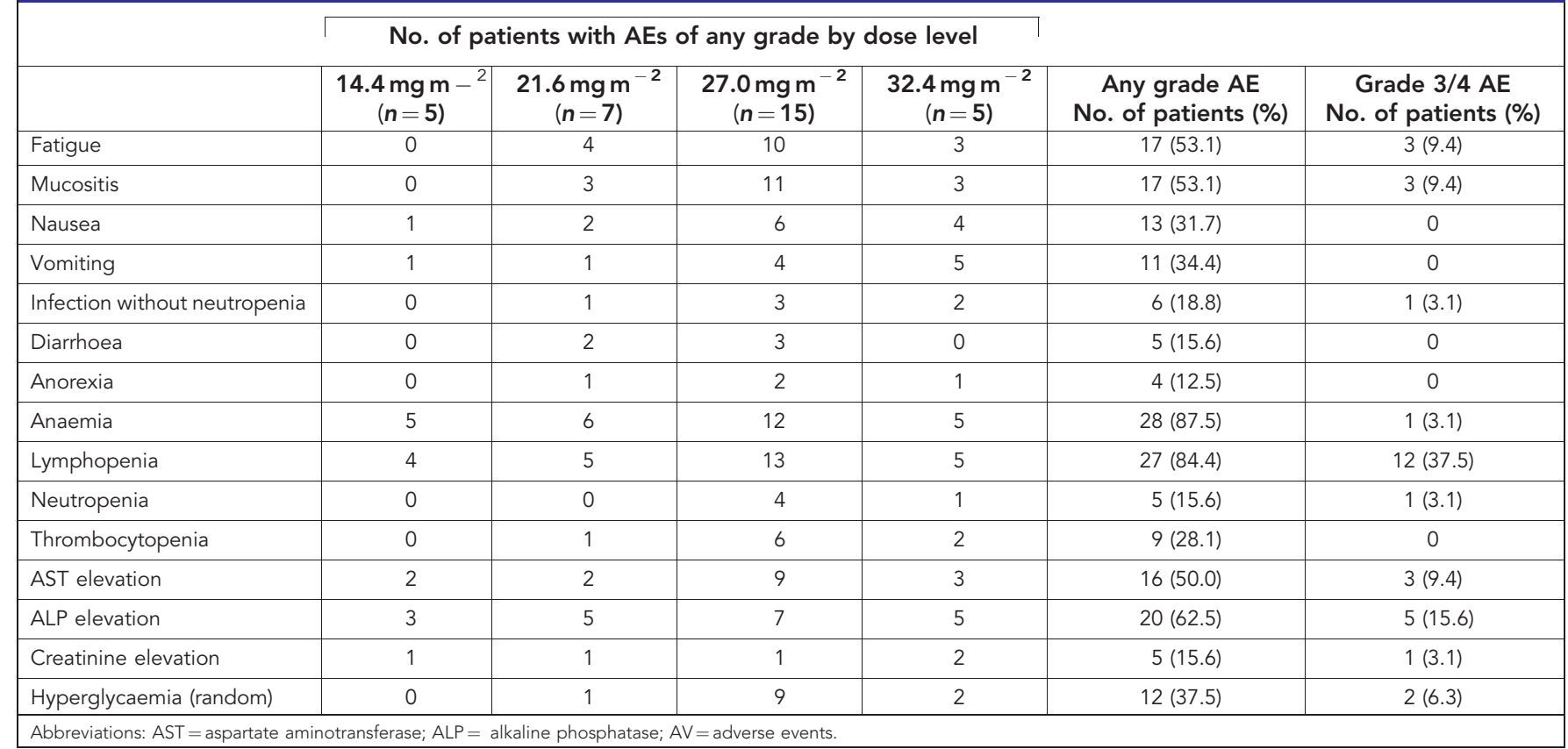

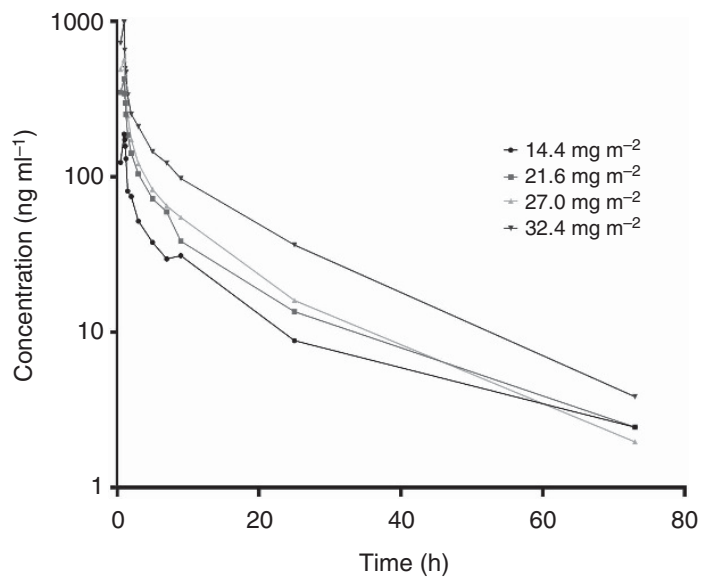

Figure 1. Mean plasma AT7519 concentration versus time by dose level.

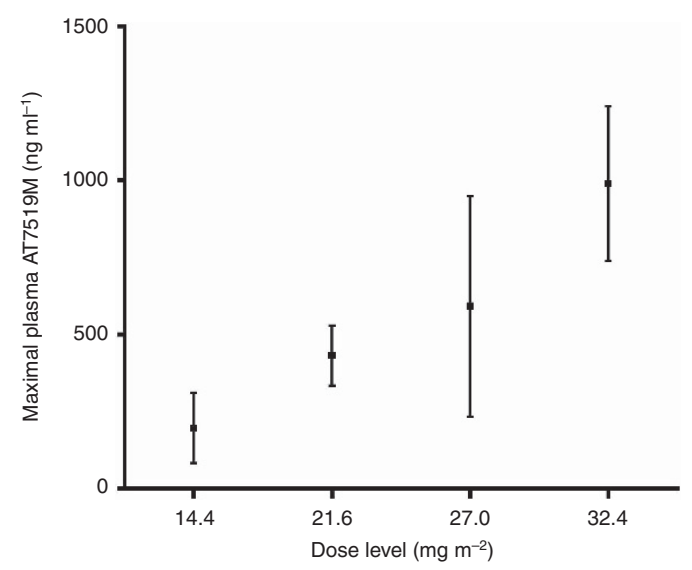

Figure 2. Plasma maximal AT7519 concentrations by dose level.

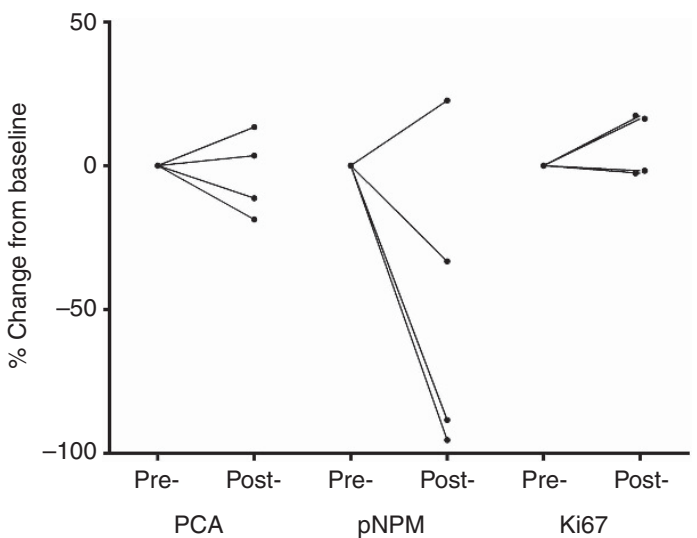

Figure 3. Changes in pharmacodynamics markers of CDK inhibition in skin punch biopsies. (markers of CDK inhibition: PCNA ( proliferating cell nuclear antigen) and pNPM (phosphor-nucleophomin); marker of cell proliferation: Ki67).

in another phase I study (Mahadevan et al, 2011). Based on these DLTs, the RP2D observed in this study was $27.0 \mathrm{mg} \mathrm{m}^{-2}$.

AT7519 was well tolerated, with most non-haematological toxicities being grade 1 and 2 events. The most common nonhaematological toxicities were fatigue, mucositis and nausea/ vomiting. However, only $9 \%$ patients had grade 3 or 4 fatigue and mucositis. Anaemia and lymphopenia were common haematological toxicities seen in $87.5 \%$ and $84.4 \%$ patients, respectively. Furthermore, grade 3 or 4 lymphopenia occurred in $37.5 \%$ patients. These observations are consistent with pre-clinical observations where AT7519 was found to induce apotosis in B-cell leukaemia cell lines through the inhibition of RNA polymerase II phosphorylation (Santo et al, 2010).

In the other phase I study, in which AT7519 was administered on five consecutive days every 3 weeks, seven dose levels were evaluated. Dose-dependent increases in QTc were observed (Mahadevan et al, 2011). One patient death from QTc prolongation was reported at the $34 \mathrm{mg} \mathrm{m}^{-2}$ per day, and the study was terminated without reaching 
the maximal tolerated dose level. Extensive QTc monitoring was performed during the current study, with serial ECGs performed. In addition, five patients had 24-h ambulatory ECG monitoring after the first drug administration at the RP2D level. No significant QTc prolongations were observed, indicating that the dosing schedule evaluated in this study is safe.

AT7519 follows linear pharmacokinetics within the dose range investigated. The $C_{\max }$ achieved at the RP2D was $591 \pm 358 \mathrm{ng} \mathrm{ml}^{-1}$. In in vitro studies, anti-cancer activities were observed at concentrations above $100 \mathrm{ng} \mathrm{ml}^{-1}$ (Squires et al, 2010). Therefore, biologically effective concentrations were achieved with the current dosing schedule. Similarly, the minimal effective biological dose was $28.8 \mathrm{mg} \mathrm{m}^{-2}$ per day from the other phase I study.

Although no partial response was seen, 10 patients had stable disease. One patient with metastatic rectal cancer achieved durable stable disease for 11.1 months. In addition, biological activity was seen. In paired pre- and post-treatment skin biopsies, three of four patients showed decreases in PNPM, consistent with CDK inhibition.

Despite the importance of CDKs in regulating cell cycle progression, targeting CDKs as a novel cancer therapy has been disappointing until recently. Among many CDK inhibitors evaluated, few have advanced beyond phase I/II evaluation (Galons et al, 2013). This lack of success has been attributed to the fact that the ATP-binding pocket of CDKs has a high degree of amino-acid conservation, inhibiting this pocket thus frequently results in pan-blockade of multiple CDKs and consequently unfavourable toxicity profiles. Recent efforts have been focusing on identifying the precise role of each CDK that plays in cell cycle regulation and developing more specific inhibitors of these CDKs. For example, CDK4 is found to be critical in the development of HER-2-positive breast cancer and KRAS mutated lung cancer, wheras CDK6 is overexpressed in lymphoma (Nagel et al, 2007; Malumbres, 2012; Kollmann et al, 2013). Specific inhibitors of CDK4/6, such as PD-0332991 and LEE011, are currently in clinical development and showing promising results (Vaughn et al, 2012; Finn et al, 2013). AT7519 inhibits CDK4/6 with $\mathrm{IC}_{50}$ of 100 and $170 \mathrm{nmoll}^{-1}$ respectively, which are well below levels achieved clinically (Squires et al, 2009). In addition, grade 3/4 lymphopenia were seen in $37.5 \%$ patients during the study, consistent with CDK6 inhibition. It is likely that AT7519 will have activity against B-cell malignancies by dual mechanisms of inhibiting CDK6 and inducing apoptosis by inhibiting RNA polymerase II phosphorylation (Santo et al, 2010). Therefore, it is rationale to focus the future development of AT7519 in B-cell malignancies.

In summary, AT7519, when administered as an intravenous infusion on days $1,4,8$ and 11 was well tolerated. The RP2D is $27.0 \mathrm{mg} \mathrm{m}^{-2}$. At this dose level, plasma AT7519 concentrations were above the biologically active concentrations, and preliminary anti-cancer activity was observed in patients. Phase II studies using this schedule are ongoing in patients with refractory multiple myeloma, chronic lymphocytic leukaemia and mantle cell lymphoma (NCT01652144 and NCT01627054).

\section{CONFLICT OF INTEREST}

Drs Lyons and Squires are employees of Astex pharmaceuticals. The remaining authors declare no conflict of interest.

\section{REFERENCES}

Bazett HC (1920) An analysis of the time-relations of electrocardiograms. Heart 7: 353-370.

Canavese M, Santo L, Raje N (2012) Cyclin dependent kinases in cancer: potential for therapeutic intervention. Cancer Biol Ther 13(7): 451-457.
Cicenas J, Valius M (2011) The CDK inhibitors in cancer research and therapy. J Cancer Res Clin 137(10): 1409-1418.

Finn RS, Dieras V, Gelmon KA, Harbeck N, Jones SE, Koehler M, Martin M, Rugo HS, Im S-A, Toi M, Gauthier ER, Huang X, Randolph S, Slamon DJ (2013) A randomized, multicenter, double-blind phase III study of palbociclib (PD-0332991), an oral CDK 4/6 inhibitor, plus letrozole versus placebo plus letrozole for the treatment of postmenopausal women with $\operatorname{ER}(+)$, HER2(-) breast cancer who have not received any prior systemic anticancer treatment for advanced disease. J Clin Oncol. Meeting Abstracts 31(15_suppl): TPS652.

Galons H, Oumata N, Gloulou O, Meijer L (2013) Cyclin-dependent kinase inhibitors closer to market launch? Expert Opin Ther Pat 23(8): 945-963.

Johnson N, Shapiro GI (2010) Cyclin-dependent kinases (cdks) and the DNA damage response: rationale for $\mathrm{cdk}$ inhibitor-chemotherapy combinations as an anticancer strategy for solid tumors. Expert Opin Ther Tar 14(11): 1199-1212.

Kim SJ, Nakayama S, Miyoshi Y, Taguchi T, Tamaki Y, Matsushima T, Torikoshi Y, Tanaka S, Yoshida T, Ishihara H, Noguchi S (2008) Determination of the specific activity of CDK1 and CDK2 as a novel prognostic indicator for early breast cancer. Ann Oncol 19(1): 68-72.

Kollmann K, Heller G, Schneckenleithner C, Warsch W, Scheicher R, Ott Rene G, Schäfer M, Fajmann S, Schlederer M, Schiefer A-I, Reichart U, Mayerhofer M, Hoeller C, Zöchbauer-Müller S, Kerjaschki D, Bock C, Kenner L, Hoefler G, Freissmuth M, Green Anthony R, Moriggl R, Busslinger M, Malumbres M, Sexl V (2013) A kinase-independent function of cdk6 links the cell cycle to tumor angiogenesis. Cancer Cell 24(2): 167-181.

Kouroukis CT, Belch A, Crump M, Eisenhauer E, Gascoyne RD, Meyer R, Lohmann R, Lopez P, Powers J, Turner R, Connors JM. National Cancer Institute of Canada Clinical Trials G (2003) Flavopiridol in untreated or relapsed mantle-cell lymphoma: results of a phase II study of the National Cancer Institute of Canada Clinical Trials Group. J Clin Oncol 21(9): 1740-1745.

Kusume T, Tsuda H, Kawabata M, Inoue T, Umesaki N, Suzuki T, Yamamoto K (1999) The p16-cyclin D1/CDK4-pRb pathway and clinical outcome in epithelial ovarian cancer. Clinl Cancer Res 5(12): 4152-4157.

Mahadevan D, Plummer R, Squires MS, Rensvold D, Kurtin S, Pretzinger C, Dragovich T, Adams J, Lock V, Smith DM, Von Hoff D, Calvert H (2011) A phase I pharmacokinetic and pharmacodynamic study of AT7519, a cyclin-dependent kinase inhibitor in patients with refractory solid tumors. Ann Oncol 22(9): 2137-2143.

Malumbres M (2012) Cell cycle-based therapies move forward. Cancer Cell 22(4): 419-420.

Nagel S, Leich E, Quentmeier H, Meyer C, Kaufmann M, Drexler HG, Zettl A, Rosenwald A, MacLeod RAF (2007) Amplification at 7q22 targets cyclin-dependent kinase 6 in T-cell lymphoma. Leukemia 22(2): 387-392.

Poomsawat S, Buajeeb W, Khovidhunkit SO, Punyasingh J (2010) Alteration in the expression of cdk4 and cdk6 proteins in oral cancer and premalignant lesions. J Oral Pathol Med 39(10): 793-799.

Santo L, Vallet S, Hideshima T, Cirstea D, Ikeda H, Pozzi S, Patel K, Okawa Y, Gorgun G, Perrone G, Calabrese E, Yule M, Squires M, Ladetto M, Boccadoro M, Richardson PG, Munshi NC, Anderson KC, Raje N (2010) AT7519, A novel small molecule multi-cyclin-dependent kinase inhibitor, induces apoptosis in multiple myeloma via GSK-3beta activation and RNA polymerase II inhibition. Oncogene 29(16): 2325-2336.

Squires MS, Cooke L, Lock V, Qi W, Lewis EJ, Thompson NT, Lyons JF, Mahadevan D (2010) AT7519, a cyclin-dependent kinase inhibitor, exerts its effects by transcriptional inhibition in leukemia cell lines and patient samples. Mol Cancer Ther 9(4): 920-928.

Squires MS, Feltell RE, Wallis NG, Lewis EJ, Smith DM, Cross DM, Lyons JF, Thompson NT (2009) Biological characterization of AT7519, a smallmolecule inhibitor of cyclin-dependent kinases, in human tumor cell lines. Mol Cancer Ther 8(2): 324-332.

Therasse P, Eisenhauer EA, Buyse M (2006) Update in methodology and conduct of cancer clinical trials. Eur J Cancer 42(10): 1322-1330.

Vaughn DJ, Gallagher M, Lal P, Rosen MA, Hwang W-T, Einhorn LH, O’Dwyer PJ (2012) Interim results of phase II trial of the cyclin-dependent kinase $4 / 6$ inhibitor PD-0332991 in refractory retinoblastoma protein positive germ cell tumors. J Clin Oncol (Meeting Abstracts) 30(15_suppl): 4596.

Wyatt PG, Woodhead AJ, Berdini V, Boulstridge JA, Carr MG, Cross DM, Davis DJ, Devine LA, Early TR, Feltell RE, Lewis EJ, McMenamin RL, Navarro EF, O'Brien MA, O’Reilly M, Reule M, Saxty G, Seavers LC, Smith DM, Squires MS, Trewartha G, Walker MT, Woolford AJ (2008) 
Identification of N-(4-piperidinyl)-4-(2,6-dichlorobenzoylamino)-1Hpyrazole-3-carboxamide (AT7519), a novel cyclin dependent kinase inhibitor using fragment-based X-ray crystallography and structure based drug design. J Med Chem 51(16): 4986-4999.
This work is published under the standard license to publish agreement. After 12 months the work will become freely available and the license terms will switch to a Creative Commons AttributionNonCommercial-Share Alike 3.0 Unported License. 